\title{
Algal Biomass as The Bioenergy Source in Meeting the Fast-Growing Energy Requirements of India: Break- through on Way to Ensure Clean Energy
}

\author{
Richa Roy* \\ Department of Biotechnology, TNB College, India \\ *Corresponding author: Richa Roy, Department of Biotechnology, TNB College, India
}

\section{ARTICLE INFO}

Received: 幽 July 23, 2019

Published: 蔧 August 01, 2019

Citation: Richa Roy. Algal Biomass as The Bioenergy Source in Meeting the Fast-Growing Energy Requirements of India: Breakthrough on Way to Ensure Clean Energy. Biomed J Sci \& Tech Res 20(2)-2019. BJSTR. MS.ID.003420.

\begin{abstract}
An effort based on preliminary research in India was made using algal biomass as the bioenergy source in meeting the fast-growing energy demand in India and across the globe. More importantly, such exploratory research would lead to a strong consensus on way to ensure clean energy under the pressing threats and challenges of climate change. Main thrust lies on enlisting of algal-fungal interactions particularly with reference to lichen being known for complex algal-fungal symbiosis and thereafter identification of suitable interactions for algal biomass harvesting through culture medium. Such approach would lead to recovery of algal biomass and conversion of bioenergy. Such bioenergy could be produced even through the involvement of rural poor women more efficiently through the "Self Help Groups" and thus, the research outcome would not only help in fulfilling the energy demand, but it will be a powerful employment provider for poor rural women in India.
\end{abstract}

Keywords: Fungal Lipids; Alternative Fuel and Biodiesel; Employment Proider; Women Empowerment

\section{Introduction}

Algal-fungal interactions are observed due to nutritional interdependency in both the species. Lichens are known for a highly complex algal-fungal symbiosis. Fungal populations are benefitted by algae due to host-parasite relationship. Such interactions may be developed for algal biomass harvesting. The recovery of algal biomass from the culture medium or wastewater is much more expensive than its cultivation. This is because of very small size of microalgal cells, ranging from 2 to $6 \mu \mathrm{m}$. This results in a situation that $40 \%$ of the total cost of algae biomass production is attributable to its cultivation compared to $60 \%$ in case of biomass recovery. SERB in the Department of Science \& Technology (2019) in India developed a method for rapid flocculation of Chlorella pyrenoids cells with Aspergillus fumigatus fungal pellets. The process could flocculate 99\% algal cells within 3 hours. Results revealed that $24 \mathrm{~h}$ old fungal pellets flocculated at $380 \mathrm{C}$ at 1:5 fungal-algal ratio gave the best flocculation efficiency. The cell viability assay showed that a viable and metabolically active fungal pellet is a prerequisite for flocculation. These results necessitated the need for investigation of the changes in surfaces properties of the algae, fungus and the algal-fungal pellet. Finally, this method was tested on wastewater grown algae, and 95\% flocculation was achieved within 3.5h.* The algal-fungal pellets (1650 $\mu \mathrm{m}$ diameter) could be easily separated from the culture. Hence, this process could serve as an alternative for concentrating microalgal cultures for biofuel production in a cost-effective way.

The above results indicated that the fungus was the driving force behind this phenomenon. However, to understand the need for a live and metabolically active fungus for the process, mechanism of this interaction was studied. The mechanism studied for the flocculation process revealed that neither algae nor fungi had any surface molecules which caused the interaction. Hence, it suggested that either the fungus or the algae secreted some molecules which 
were triggering this process. Analysis of the fungal used medium showed that there was some extracellular factor which aided in the flocculation process. Microscopic examination of fungal spent medium incubated algal cells showed the formation of pilus-like structures on the algal cell surface. Biochemical analysis of the fungal spent medium indicated that the active molecule might be sugar like molecule. High-resolution liquid chromatography-mass spectrometry (HR-LC-MS) analysis of the fungal spent medium led to the identification of N-acetyl glucosamine (GlcNAc) which had a role in the flocculation process. Further studies with GlcNAc incubated algal cells confirmed its role in the flocculation process. Although numerous studies have been reported in the recent time, no workable mathematical model has been developed for the same. For the first time, researchers proposed a mathematical model for this type of system.

The model shows that the process is not a second-order process, unlike other flocculation models. The process is also dependent on the radius of the algal cells and fungal pellets. Moreover, the flocculation process is affected by the velocity gradient of the system. The model was validated using different experiments viz. different fungal-algal ratio, variation in rpm, different algal strains, algae grown in different wastewaters and finally in a $10 \mathrm{~L}$ photobioreactor. The proposed model is found to be in agreement with the experimental results along with $\mathrm{r} 2>0.90$ in most of the cases. The flocculation process was then carried out in a 10 l photobioreactor. The results showed that $85 \%$ of the algal cells were harvested within 4 hours [1].

\section{Basic Activities and Procedures/Methodology}

Algae can be used to produce biofuel, biobutanol, biogasoline, methanol, methane, ethanol, and even jet fuel. For this, the algae must be harvested (killed), the oil extracted and then the oil refined to produce a fuel. This is usually the case with traditional fuels like jet fuel, biogasoline or biodiesel. The problem with such an approach is that growing algae from scratch requires more nutrients than if they are simply maintained. To that end, several companys and institutions have developed ways to harvest ethanol, butanol and even biodiesel from algae that excrete the fuel into water they are grown in. Only two species of Algae; Aspergillus fumigates and A Fumigates were used. However, to produce same amount of biofuel with algae as compared to jatropha requires around 400 times less land. To supply the aviation industry would require 2.7 million kilometres of jatropha and only 68,000 sq km of algae. In terms of indirect land use change using algae allows for growth on marginal land. A number of algae are genetically modified (GM algae) and fall under patent protection.

Open pond growth is the most common system used to produce algae that will be harvested for their high oil content. It is also the most similar to how algae would be grown naturally. The benefits to this system lie with fact that it requires little capital investment and components of the system require less maintenance. It is widely recognized that the lichen is the product of a fungus and a photosynthetic partner (green algae or cyanobacterium), but its acceptance was slow to develop throughout history. The development of powerful microscopic and other lab techniques enabled better understanding of the interface between symbionts, beginning with the contentious concept of the dual nature of the lichen thallus. Even with accelerating progress in understanding the interface between symbionts, much more work is needed to reach a level of knowledge consistent with that of other fungal interactions. This mini review describes the interface between algal and fungal symbionts in lichens, including the appearance of interacting symbionts, our current understanding of communication between symbionts, and emerging new concepts in light of the challenges and debates that have provided lichenology with an enriched history. Communication between symbionts occurs before physical contact, which has been studied through microscopy, movement of molecules between symbionts, and gene expression studies. New discoveries include the interaction with more than one alga in a lichen thallus as well as other unrelated fungi and bacteria typically found on or within the thallus.

Lichens are a fascinating example of a symbiotic mutualism.

It is still uncertain which processes guide fungal-photobiont interactions, and whether they are random or of a more complex nature. Here, I analyze the fungal-algal interactions in Ramalina menziesii and co-occurring taxa. Using DNA sequences of the algal Internal Transcribed Spacer region (ITS), I investigated fungal-algal associations in juvenile R. menziesii and allied species. Algal species were identified by a combination of BLAST searches, median-joining network analysis, and Bayesian phylogenetics. I analyzed fungalalgal networks for nestedness, both at the species and haplotypelevel (fungal species vs. algal haplotypes) and inspected the networks for evidence of compartmentalization [2]. Bayesian phylogenetic trees indicated that the widespread green alga Trebouxia decolorans associated with R. menziesii, as well as six other fungal species. Four additional fungal species interacted with four different species of Trebouxia. Only in one out of ten samples were algal haplotypes shared with the nearest neighbors of juvenile R. menziesii. Fungalalgal species interactions were compartmentalized, while at the level of algal haplotypes, nestedness was found. This pattern is similar to the compartmentalization found in other intimately interacting mutualists.

New generation energy sources is very much essential in Indian and global context. The available renewable sources have to be optimized to give maximum biofuel returns.

The selective techniques have been imprisoned on the research institutes and University laboratories. The major sources includes Algae, Jatropha oil and vegetable oils, cellulosic materials, corn and sugarcane etc. have been under surveillance since late 1990s. Major drawback so far for renewable energy sources are continuous flow of energy of biofuel from a single one. Overestimation of potential 
of Jatropha oil, as a potent source has been identified and slowly rejected by growers and the planners. Algae, one of the most effective sources of biodiesel, production technique and availability of water sources has been under scanner. The conversion of vegetable oil and food grain sources for biodiesel got thumb down indicator from many. The new addition of cellulosic biofuel as a second-generation biofuel has abundant availability of raw material [3]. But it required a lot of research hours to confirm the best suitable technique and the best source for economically viable production system. Under the mentioned constraints, lays the hope and assurance for finding best source and technique to produce biofuel for the use of masses. As, the conventional sources of energy drying up at faster rate, the alternate sources be explored, examined and implemented in no time.

\section{Lichen Growth/Mat}

A fresh rock surface or a brick wall during rainy season in presence of varying intensity of light forms a green mat of lichens or algae on it. Growing of such green mat or layer even on a wet soil during rainy season is widely witnessed across the globe. Even the blue green algae and phototrophic microorganisms in wet season do appear on the rock and allow a growing environment to many small plants (Figure 1). A lichen as the plant species is a mixture of fungus (one species) and of algae (another) and both species work together and thus behave like a single organism, wherein the fungus gives shape to the lichen and the algal cells lie spread between the thread-like fungal cells. The algae produce carbohydrates and other organic molecules for nourishment and the fungus by means of photosynthesis. Besides, the fungus furnishes minerals, humidity and protection for the algae, and keeps the algae exposed to the sun. However, both of species are capable of growing alone. The fungus of lichens have a mutualistic symbiotic relationship with algae. The fungi provide protection and moisture to the algae, and the algae feed the fungi with photosynthetic nutrients. the symbiotic, or mutually beneficial relationship, is between a green alga (cyanobacterium) and a fungus. The algal partner is capable of creating energy through its green pigment called chlorophyl and the combination of water and carbon dioxide from the air along with energy from sunlight. It seems that algae and its association with fungi may fulfil partial dependence on fossil fuels, although making this unique association or even algae alone as a biofuel needs careful follow-up of the processes involved [4]. There are a number of mechanical and chemical methods to extract oil even from algae and convert it to fuel that is actually viable ecologically and economically. Algae-based biofuel production has successfully commercialized in America (U.S. Department of Energy) [5].
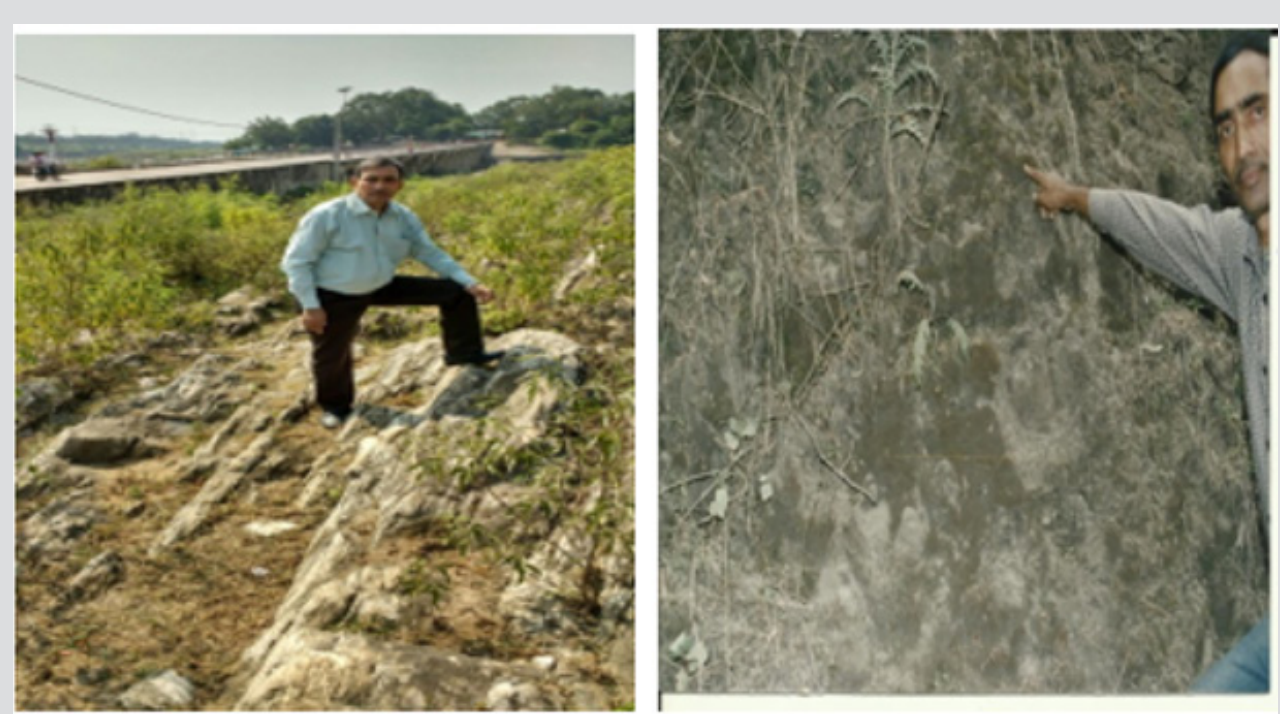

Figure 1: Lichen on marble (Jabalpur) and basalt (Mumbai).

\section{Conclusions}

The scarceness of fossil-based fuels and the environmental impact produced by the conventional sources of energy over the planet, has lead new research work to seek the sustainable sources of clean energy. Biofuel is committed to becoming a worldwide leader in the development and deployment of renewable energy resources. Biodiesel is an alternative fuel, made from renewable biological sources. Biodiesel can also be produced from microbial sources like algae, bacteria and fungi. Fungi exhibit the capacity to accumulate intracellular lipids in excess of 70 percent of their biomass during metabolic stress periods. Fungal lipids as a source for biodiesel was less studied. Hence the fungal lipids source as diesel fuel was taken for this study. The invented method is a unique process of its kind and has potential application in algaebased biofuel production including biomethane, biohydrogen and biodiesel as well as in the extraction of other valuable compounds from microalgal biomass.

\section{Acknowledgement}

Thanks to the SERB in the Department of Science \& Technology (2019) in India for similar contribution. Thanks to Nithya Devi .M 
(Research Scholar, 12, VST Street, Tiruvarur - 610002, TamilNadu, India; Email: nithyadevi77@gmail.com) and Velayudam (Reader in Botany, Government Arts College, Karur - 639 005, TamilNadu, India) for their contributions on Biodiesel Production from Fungi in 2011.

\section{References}

1. Michele D Piercey-Normore, Sarangi NP Athukorala (2017) Interface between fungi and green algae in lichen associations1. Botany 95(10) 1005-1014.

\section{ISSN: 2574-1241}

DOI: $10.26717 /$ BJSTR.2019.20.003420

Richa Roy. Biomed J Sci \& Tech Res

(C) This work is licensed under Creative

Submission Link: https://biomedres.us/submit-manuscript.php
2. Katie Howell (2009) Scientific American.com (2010) Is Algae the Biofuel of the Future? April 28, 2009.

3. Silke Werth (2012) Fungal-algal interactions in Ramalina menziesii and its associatedepiphytic lichen community. The Lichenologist 44(4): 543-560.

4. Swain KC (2014) Biofuel Production in India: Potential, Prospectus and Technology. Journal of Fundamental Renewable Energy Application 4: 129.

5. (2010) U.S. Department of Energy Department of Energy Announces \$24 Million for Algal Biofuels Research. June 282010.

$\begin{array}{ll}\text { BIOMEDICAL } & \text { Assets of Publishing with us } \\ \text { RESEARCHES } & \text { - Global archiving of articles } \\ & \text { - Immediate, unrestricted online access } \\ \end{array}$

